\title{
Does COPD risk vary by ethnicity? A retrospective cross-sectional study
}

\author{
This article was published in the following Dove Press journal: \\ International journal of COPD \\ 7 April 2016 \\ Number of times this article has been viewed
}

\section{Alexander Gilkes \\ Mark Ashworth \\ Peter Schofield \\ Timothy H Harries \\ Stevo Durbaba \\ Charlotte Weston \\ Patrick White}

Department of Primary Care and Public Health Sciences, Division of Health and Social Care Research,

Kings College London, London, UK
Correspondence: Alexander Gilkes Department of Primary Care and Public Health Sciences, Division of Health and Social Care Research, Kings College London, 3rd Floor Addison House, Guy's Campus, London SEI IUL, UK

Tel +442078488680

Email alexander.gilkes@kcl.ac.uk
Background: Lower risk of COPD has been reported in black and Asian people, raising questions of poorer recognition or reduced susceptibility. We assessed prevalence and severity of COPD in ethnic groups, controlling for smoking.

Method: A retrospective cross-sectional study using routinely collected primary care data in London. COPD prevalence, severity (\% predicted forced expiratory volume in 1 second $\left[\mathrm{FEV}_{1}\right]$ ), smoking status, and treatment were compared between ethnic groups, adjusting for age, sex, smoking, deprivation, and practice clustering.

Results: Among 358,614 patients in 47 general practices, 47.6\% were white, 20\% black, and $5 \%$ Asian. Prevalence of COPD was $1.01 \%$ overall, $1.55 \%$ in whites, $0.58 \%$ in blacks, and $0.78 \%$ in Asians. COPD was less likely in blacks (adjusted odds ratio [OR], $0.44 ; 95 \%$ confidence interval [CI] 0.39-0.51) and Asians (0.82; CI, 0.68-0.98) than whites. Black COPD patients were less likely to be current smokers (OR, 0.56; CI, 0.44-0.71) and more likely to be never-smokers (OR, 4.9; CI, 3.4-7.1). Treatment of patients with similar disease severity was similar irrespective of ethnic origin, except that long-acting muscarinic antagonists were prescribed less in black COPD patients (OR, 0.53; CI, 0.42-0.68). Black ethnicity was a predictor of poorer lung function ( $\%$ predicted $\mathrm{FEV}_{1}$ : B coefficient, $-7.6 ; P<0.0001$ ), an effect not seen when ethnic-specific predicted $\mathrm{FEV}_{1}$ values were used.

Conclusion: Black people in London were half as likely as whites to have COPD after adjusting for lower smoking rates in blacks. It seems likely that the differences observed were due either to ethnic differences in the way cigarettes were smoked or to ethnic differences in susceptibility to COPD.

Keywords: COPD, smoking, ethnicity

\section{Introduction}

In the only population study to assess COPD prevalence by ethnicity to date, Martin et $\mathrm{al}^{1}$ found a lower prevalence of COPD among black and Asian people compared to white people, although there were relatively small numbers of black people in their study. Black and Asian COPD patients reported less severe breathlessness than white patients, although their severity according to \% predicted forced expiratory volume in 1 second $\left(\mathrm{FEV}_{1}\right)$ was not significantly different. White et $\mathrm{al}^{2}$ found that $8.5 \%$ of patients diagnosed with COPD in a South London population were black, compared to $25.8 \%$ of the local population overall, although ethnicity data were only available on $54.8 \%$ of the study population. The apparent lower prevalence of COPD in black people raises the question whether this is due to poorer detection or lower risk of disease.

Nacul et $\mathrm{al}^{3}$ predicted that the highest prevalence of COPD would be among black men in deprived areas, using the relatively small numbers of data from the Health Survey for England. Mortality from COPD appears higher in blacks in the USA. ${ }^{4}$ Eisner et $\mathrm{al}^{5}$ 
found more severe disease in black COPD patients, but this effect disappeared when accounting for household income and educational attainment. Han et $\mathrm{al}^{6}$ found increased hospital admissions and adverse effects on quality of life because of COPD among black patients compared to white patients. Cannon et $\mathrm{al}^{7}$ found that black patients with COPD exacerbation were more likely to receive mechanical ventilation in hospital. Mowls et $\mathrm{al}^{8}$ found that blacks with COPD were more likely to have had spirometry performed. A US cross-sectional study found that black ethnicity did not affect the relationship between cigarette exposure and deterioration in lung function, but it did not examine clinical COPD diagnosis. ${ }^{9}$

COPD is an important health burden. ${ }^{10}$ It accounts for over 25,000 deaths in the $\mathrm{UK}^{11}$ and is the second biggest cause of emergency hospital admissions. ${ }^{12,13}$ The main risk factor for COPD in the UK is cigarette smoking. ${ }^{10}$

Spirometry, upon which the diagnosis and severity classification of COPD depends, differs in healthy individuals between ethnic groups. US studies have suggested that predicted $\mathrm{FEV}_{1}$ and predicted forced vital capacity (FVC) based on height may be overestimated by $12 \%$ in black subjects. ${ }^{14,15}$ A London study demonstrated that white people have higher mean FVC than black and Asian people when controlling for height and sex, but there was no difference in $\mathrm{FEV}_{1} / \mathrm{FVC}$ ratio (implying that $\mathrm{FEV}_{1}$ was also lower in black and Asian people). ${ }^{16}$ Lower FVC in black people is associated with higher mortality than in white people when controlling for $\mathrm{FEV}_{1} / \mathrm{FVC}$ ratio, age, height, and sex. ${ }^{17}$ This led Burney and Hooper ${ }^{17}$ to suggest that "normal" spirometry values should be the same for different ethnic groups for prognostic purposes, to take into account higher mortality associated with lower FVC. An adjustment for ethnicity is currently recommended in the UK by the British Thoracic Society (BTS) and the Association for Respiratory Technology and Physiology, ${ }^{18}$ but it is unclear how widely this is actually performed.

The observation of differences between ethnic groups in the prevalence of COPD and in the predicted values of spirometry demands closer examination. A better appreciation of ethnic differences in disease susceptibility and disease burden will enable us to target health inequalities and improve our understanding of disease pathogenesis and treatment. ${ }^{19}$ In this study, we have examined ethnic differences at a population level in the prevalence, severity, and treatment of COPD in London.

\section{Method}

\section{Study design}

This retrospective cross-sectional study used routinely collected primary care data to assess the prevalence of COPD and its patient and practice predictors. Lambeth DataNet, an anonymized primary care database, has data from all electronic patient records from 47 out of 48 general practices in the London Borough of Lambeth. Data were collected with the approval of Lambeth Information Governance Committee (October 2013). The data, anonymized prior to being received for this analysis, was defined by the South London Primary Care Research Governance Team, St George's Hospital Medical School, London, as audit style and therefore not requiring research governance or ethical approval.

\section{Sample}

All patients of all ages registered with 47 participating general practices in Lambeth on October 31, 2013 were eligible. Data were extracted on October 31, 2013. Data had been collected over 30 preceding years, but mostly in the preceding 3 years. Where there were multiple values for a variable, the most recent value was used. All patients with a current diagnosis of COPD, (including emphysema, chronic bronchitis, and other International Classification of Diseases, Revision 10 diagnostic codes J41-J44.9 consistent with COPD) were used to calculate prevalence of COPD. A subgroup of spirometry-confirmed COPD was identified: those with a recorded diagnosis of COPD and Global Initiative for Chronic Obstructive Lung Disease (GOLD)-defined obstructive spirometry (ratio of $\mathrm{FEV}_{1} / \mathrm{FVC}<0.7$ ). ${ }^{20}$

\section{Measures}

COPD severity was defined by $\%$ predicted $\mathrm{FEV}_{1}$. When $\%$ predicted $\mathrm{FEV}_{1}$ was not recorded but $\mathrm{FEV}_{1}$, age, and height were available, we calculated \% predicted $\mathrm{FEV}_{1}$ using the European Coal and Steel Community (ECSC) reference equations, ${ }^{21}$ as recommended by BTS. ${ }^{18}$

Binary variables (yes/no) were created for each class of COPD medication, which were positive if they had been prescribed in the preceding year. Strength, dosage, and volume of prescribed medications were not recorded. Medications were categorized as: short-acting $\beta$ agonists (SABA), short-acting muscarinic antagonists (SAMA), long-acting $\beta$ agonists (LABA), long-acting muscarinic antagonists (LAMA), inhaled corticosteroids (ICS), ICS/LABA combinations, oral steroids, theophyllines, and mucolytics.

Self-reported ethnicity was recorded by practices according to the UK 2001 Census ethnic group (and subgroup) categories: white (white British/mixed; Irish white; Other white); mixed (white and black Caribbean; white and black African; white and Asian; mixed other); Asian or Asian British (Indian/British Indian; Pakistani/British Pakistani; Bangladeshi; other Asian); black or black British (Caribbean; African; other black); Chinese/other (Chinese; other ethnic 
group); unknown; and not stated.22 The Asian category in the UK census ethnicity categories refers to people of south Asian background (Indian, Pakistani, and Bangladeshi nationalities). This is different from the census categories in other societies, which may include those of south-east Asian and Far East origin (including Japan and the People's Republic of China) in the category Asian. ${ }^{23}$

The most recently entered smoking code was used to label each patient as a current smoker, ex-smoker, or never smoker. Where there were conflicting smoking codes in the same patient, the most appropriate code was applied (eg, patients with recent "never smoked tobacco" and previous "smoker" were recoded as "ex-smoker").

An Index of Multiple Deprivation (IMD-10) score for social deprivation was assigned at patient level and mapped to lower super output area using postcode. IMD score is based on national census and local authority data, and reflects deprivation specific to geographical areas. ${ }^{24}$ IMD scores in 2010 ranged nationally from 0 (least deprived) to 88 (most deprived).

\section{Statistical analysis}

Raw prevalence of COPD was calculated for the whole population and for each ethnic group. Likelihood of COPD diagnosis was compared between ethnic groups using multiple logistic regression, adjusting for age, sex, smoking, IMD score, and practice clustering. Among COPD patients, the following were compared between ethnic groups: treatment with each class of medication using multiple logistic regression; \% predicted $\mathrm{FEV}_{1}$ (as a marker of severity) using multiple linear regression; and likelihood of being a current smoker or a never-smoker using multiple logistic regression. Patients with ethnicity unknown or not stated were excluded from regression analyses, because these were not felt to be valid descriptors of ethnicity.

Stata software version 13 (StataCorp LP, College Station, TX, USA) was used for all statistical analysis.

\section{Sensitivity analyses}

The main COPD analysis was repeated using confirmed COPD as the dependent variable to see if excluding those with a COPD diagnosis without spirometry confirmation affected the relationship between ethnicity and risk of COPD.

The linear regression analysis for COPD severity was repeated after adjusting for ethnicity by reducing predicted $\mathrm{FEV}_{1}$ by $13 \%$ for black patients and $7 \%$ for Asian patients, as recommended by the BTS ${ }^{18}$ and consistent with several US studies. ${ }^{14,15,25}$

\section{Results \\ Participants}

Data were collected on 358,614 patients across 47 practices. Overall population characteristics are shown in Table 1, with the characteristics of COPD patients in Table 2. Ethnicity data were recorded for $81.3 \%$ of all patients and $91.7 \%$ of COPD patients. Smoking status was recorded for $82 \%$ of all patients and $99.8 \%$ of COPD patients.

All minority ethnic groups, but especially black people, were significantly less likely than white people to have a diagnosis of COPD when controlling for age, sex, smoking, deprivation, and practice clustering (Table 3). Repeating the analysis with spirometry-confirmed COPD as the dependent variable did not significantly affect the results. The analysis was extended to ethnic subgroups, controlling for the same factors, revealing high prevalence of COPD among white Irish (Table 3).

\section{Smoking history}

Among COPD patients, black patients were significantly less likely to be current smokers than white patients (OR, 0.56 ; CI, 0.44-0.71) after controlling for age, sex, IMD score, and practice clustering (Table 4). They were also five times more likely to have never smoked than white patients (adjusted

Table I Characteristics of the whole population (age, sex, smoking status, IMD score, COPD diagnosis, and spirometry-confirmed COPD) by ethnic group

\begin{tabular}{|c|c|c|c|c|c|c|c|c|c|c|}
\hline Ethnic group & $\mathbf{N}(\%)$ & $\begin{array}{l}\text { Mean } \\
\text { age } \\
\text { (years) }\end{array}$ & $\begin{array}{l}\text { Male } \\
(\%)\end{array}$ & $\begin{array}{l}\text { Current } \\
\text { smoker } \\
(\%)\end{array}$ & $\begin{array}{l}\text { Ex-smoker } \\
(\%)\end{array}$ & $\begin{array}{l}\text { Never } \\
\text { smoker } \\
(\%)\end{array}$ & $\begin{array}{l}\text { Smoker } \\
\text { status } \\
\text { unknown (\%) }\end{array}$ & $\begin{array}{l}\text { Mean } \\
\text { IMD } \\
\text { score }\end{array}$ & $\begin{array}{l}\text { Recorded } \\
\text { COPD } \\
\text { diagnosis (\%) }\end{array}$ & $\begin{array}{l}\text { Spirometry- } \\
\text { confirmed } \\
\text { COPD (\%) }\end{array}$ \\
\hline White group & I70,632 (48) & 37 & 49 & 22 & 24 & 43 & II & 30 & 1.55 & 0.77 \\
\hline Black or black British & $71,836(20)$ & 35 & 47 & 14 & 14 & 51 & 20 & 34 & 0.58 & 0.26 \\
\hline Asian or Asian British & 18,770 (5) & 36 & 53 & 13 & 13 & 59 & 15 & 27 & 0.78 & 0.34 \\
\hline Mixed & 16,803 (5) & 28 & 46 & 18 & 14 & 40 & 28 & 32 & 0.50 & 0.17 \\
\hline Chinese/other & $13,650(4)$ & 35 & 47 & 15 & 16 & 55 & 15 & 32 & 0.34 & 0.13 \\
\hline Unknown & $57,107(16)$ & 33 & 55 & 17 & 13 & 39 & 32 & 31 & 0.41 & 0.15 \\
\hline Not stated & $9,816(3)$ & 30 & 51 & 15 & 15 & 36 & 34 & 31 & 0.65 & 0.29 \\
\hline All & 358,614 & 35 & 49 & 18 & 19 & 45 & 18 & 31 & I.0I & 0.48 \\
\hline
\end{tabular}

Abbreviation: IMD, index of multiple deprivation. 
Table 2 Characteristics of COPD patients (age, sex, smoking status, IMD score, and spirometry-confirmed COPD) by ethnic group

\begin{tabular}{llllllllll}
\hline Ethnic group & $\mathbf{N}(\%)$ & $\begin{array}{l}\text { Mean } \\
\text { age } \\
\text { (years) }\end{array}$ & $\begin{array}{l}\text { Male } \\
(\%)\end{array}$ & $\begin{array}{l}\text { Current } \\
\text { smoker } \\
(\%)\end{array}$ & $\begin{array}{l}\text { Ex-smoker } \\
(\%)\end{array}$ & $\begin{array}{l}\text { Never } \\
\text { smoker } \\
(\%)\end{array}$ & $\begin{array}{l}\text { Smoker } \\
\text { status } \\
\text { unknown (\%) }\end{array}$ & $\begin{array}{l}\text { Mean } \\
\text { IMD } \\
\text { score }\end{array}$ & $\begin{array}{l}\text { Spirometry- } \\
\text { confirmed } \\
\text { COPD (\%) }\end{array}$ \\
\hline White group & $2,637(73)$ & 68 & 52 & 43 & 52 & 5 & 0.1 & 32 & 50 \\
Black or black British & $416(11)$ & 69 & 69 & 31 & 52 & 16 & 0.5 & 34 & 44 \\
Asian or Asian British & $146(4)$ & 67 & 75 & 35 & 46 & 19 & 0.0 & 31 & 44 \\
Mixed & $84(2)$ & 66 & 57 & 40 & 43 & 17 & 0.0 & 34 & 33 \\
Chinese/other & $47(1)$ & 65 & 70 & 21 & 51 & 28 & 0.0 & 30 & 38 \\
Unknown & $236(7)$ & 68 & 60 & 40 & 47 & 11 & 1.7 & 32 & 36 \\
Not stated & $64(2)$ & 70 & 69 & 30 & 56 & 14 & 0.0 & 30 & 44 \\
All & 3,630 & 68 & 56 & 41 & 51 & 8 & 0.2 & 32 & 48 \\
\hline Abta
\end{tabular}

Abbreviation: IMD, index of multiple deprivation.

Table 3 Comparison of likelihood of COPD diagnosis and spirometry-confirmed COPD diagnosis between ethnic groups and subgroups, with white and white British as baseline

\begin{tabular}{|c|c|c|c|c|c|c|c|}
\hline Ethnic group & $\begin{array}{l}\text { COPD } \\
\text { diagnosis } \\
\text { OR }\end{array}$ & $\begin{array}{l}95 \% \\
\text { confidence } \\
\text { interval }\end{array}$ & $\begin{array}{l}\text { Spirometry- } \\
\text { confirmed } \\
\text { COPD } \\
\text { OR }\end{array}$ & $\begin{array}{l}95 \% \\
\text { confidence } \\
\text { interval }\end{array}$ & Ethnic subgroup & $\begin{array}{l}\text { COPD } \\
\text { diagnosis } \\
\text { OR }\end{array}$ & $\begin{array}{l}95 \% \\
\text { confidence } \\
\text { interval }\end{array}$ \\
\hline \multirow[t]{3}{*}{ White } & I & & I & & White British/mixed & I & \\
\hline & & & & & Irish white & 1.35 & $1.13-1.62$ \\
\hline & & & & & Other white & 0.55 & $0.46-0.67$ \\
\hline \multirow[t]{3}{*}{ Black or black British } & 0.44 & $0.39-0.51$ & 0.42 & $0.36-0.49$ & Caribbean & 0.45 & $0.38-0.52$ \\
\hline & & & & & African & 0.32 & $0.25-0.41$ \\
\hline & & & & & Other black & 0.26 & $0.18-0.39$ \\
\hline \multirow[t]{4}{*}{ Asian or Asian British } & 0.82 & $0.68-0.98$ & 0.74 & $0.57-0.96$ & Indian/British Indian & 0.65 & $0.47-0.90$ \\
\hline & & & & & Pakistani/British Pakistani & 0.95 & $0.6 \mathrm{I}-\mathrm{I} .50$ \\
\hline & & & & & Bangladeshi & 0.63 & $0.37-1.07$ \\
\hline & & & & & Other Asian & 0.76 & $0.60-0.97$ \\
\hline \multirow[t]{4}{*}{ Mixed } & 0.70 & $0.49-0.98$ & 0.49 & $0.32-0.74$ & White and black Caribbean & 0.76 & $0.47-1.25$ \\
\hline & & & & & White and black African & 0.21 & $0.09-0.5 \mathrm{I}$ \\
\hline & & & & & White and Asian & 0.61 & $0.28-1.36$ \\
\hline & & & & & Mixed other & 0.67 & $0.49-0.91$ \\
\hline \multirow[t]{2}{*}{ Chinese/other } & 0.41 & $0.28-0.60$ & 0.34 & $0.16-0.70$ & Chinese & 0.34 & $0.21-0.58$ \\
\hline & & & & & Other ethnic group & 0.38 & $0.23-0.63$ \\
\hline
\end{tabular}

Notes: Multiple logistic regression controlling for age, sex, smoking status, deprivation, and practice clustering. Excludes people with no recording of ethnicity ( $\mathrm{n}=247,939)$. Bold indicates significance, $P<0.05$.

Abbreviation: OR, odds ratio.

Table 4 Comparison of smoking history in COPD patients between ethnic groups $(n=3,330)$

\begin{tabular}{|c|c|c|c|c|c|c|c|}
\hline Ethnic group & Frequency & $\begin{array}{l}\text { \% currently } \\
\text { smoking }\end{array}$ & $\begin{array}{l}\text { OR for currently } \\
\text { smoking }\end{array}$ & $95 \% \mathrm{Cl}$ & $\begin{array}{l}\% \text { never } \\
\text { smoked }\end{array}$ & $\begin{array}{l}\text { OR for never } \\
\text { smoked }\end{array}$ & $95 \% \mathrm{Cl}$ \\
\hline White & 2,637 & 43.2 & 1 & & 4.8 & 1 & \\
\hline Black & 416 & 31.5 & 0.56 & $0.44-0.71$ & 15.6 & 4.9 & $3.4-7.1$ \\
\hline Asian & 146 & 34.9 & 0.69 & $0.47-1.02$ & 19.2 & 6.5 & $3.7-11.4$ \\
\hline Mixed & 84 & 40.5 & 0.79 & $0.53-1.18$ & 16.7 & 4.7 & $2.3-9.6$ \\
\hline Chinese/other & 47 & 21.3 & 0.28 & $0.15-0.52$ & 27.7 & 10.6 & $4.6-24.3$ \\
\hline
\end{tabular}

Notes: Current smokers were compared with current nonsmokers and never smokers were compared with ever smokers using multiple logistic regression, controlling for age, sex, deprivation score, and practice clustering. Excludes people with no recording of ethnicity. Bold indicates statistical significance, $P<0.05$.

Abbreviations: $\mathrm{OR}$, odds ratio; $\mathrm{Cl}$, confidence interval. 
Table 5 Comparison of COPD severity (\% predicted FEV $)$ between ethnic groups among all COPD patients $(n=2,824)$ and spirometryconfirmed COPD patients $(\mathrm{n}=\mathrm{I}, 509)$

\begin{tabular}{|c|c|c|c|c|c|c|}
\hline \multirow[t]{2}{*}{ Ethnic group } & \multicolumn{3}{|c|}{$\begin{array}{l}\text { \% predicted FEV } \\
\text { (ECSC-derived predicted values) }\end{array}$} & \multicolumn{3}{|c|}{$\begin{array}{l}\text { \% predicted FEV } \\
\text { (ethnicity-specific predicted values) }\end{array}$} \\
\hline & B coefficient & $95 \% \mathrm{Cl}$ & Standardized $\beta$ & B coefficient & $95 \% \mathrm{Cl}$ & Standardized $\beta$ \\
\hline \multicolumn{7}{|c|}{ All COPD patients $(n=2,824)$} \\
\hline \multicolumn{7}{|l|}{ White } \\
\hline Black or black British & -7.59 & -10.0 to -5.2 & -0.111 & -1.09 & -1.6 to 3.8 & 0.016 \\
\hline Asian or Asian British & -4.23 & -7.1 to -1.3 & -0.038 & 0.37 & -2.7 to 3.4 & 0.003 \\
\hline Mixed & -4.95 & -10.0 to 0.1 & 0.033 & -4.95 & -10.1 to 0.1 & -0.032 \\
\hline Chinese/other & -3.08 & -9.7 to 3.5 & 0.016 & -3.10 & -9.7 to 3.5 & -0.016 \\
\hline \multicolumn{7}{|c|}{ Spirometry-confirmed COPD $(n=I, 509)$} \\
\hline \multicolumn{7}{|l|}{ White } \\
\hline Black or black British & -8.99 & -12.00 to -5.97 & -0.140 & -1.63 & -5.02 to 1.76 & 0.016 \\
\hline Asian or Asian British & -5.12 & -10.22 to -0.02 & -0.050 & -1.14 & -6.58 to 4.30 & 0.003 \\
\hline Mixed & -7.48 & $-\mid 5.27$ to $0.3 \mid$ & 0.050 & -7.46 & -15.27 to 0.34 & -0.032 \\
\hline Chinese/other & -2.46 & -9.61 to 4.69 & 0.012 & -2.48 & -9.63 to 4.67 & -0.016 \\
\hline
\end{tabular}

Notes: A sensitivity analysis using ethnicity-specific predicted FEV, values is included. Multiple linear regression controlling for age, sex, smoking status, deprivation, and practice clustering. Excludes people with no recording of ethnicity. Bold indicates statistical significance, $P<0.05$.

Abbreviations: ECSC, European Coal and Steel Community; $\mathrm{FEV}_{1}$, forced expiratory volume in I second; $\mathrm{Cl}$, confidence interval.

OR, 4.9; CI, 3.4-7.1). All ethnic groups were significantly more likely to have never smoked than the white group.

\section{Access to spirometry}

In the whole population, black people were significantly less likely to have spirometry performed, whatever the result (adjusted OR, 0.64; CI, 0.58-0.70). Among COPD patients, black patients were significantly more likely to have had spirometry performed than white patients (adjusted OR, 1.55; CI, 1.06-2.26). There was no significant ethnic difference in the likelihood of COPD being confirmed on spirometry.

\section{Prescribing among COPD patients}

There were no significant ethnic differences in the likelihood of being prescribed SABA, SAMA, LABA, ICS, ICS/ LABA, oral steroids, or mucolytics, when controlling for age, sex, deprivation, smoking, and COPD severity. LAMAs were less likely to be prescribed in black people than white people (OR, 0.53; CI, 0.42-0.68; $\mathrm{n}=1,667)$. Theophyllines were more likely to be prescribed in Asian people (OR, 3.92; CI, $1.23-12.5 ; \mathrm{n}=32$ ).

\section{Severity of COPD}

Black ethnicity was a significant predictor of lower $\%$ predicted $\mathrm{FEV}_{1}$ (B coefficient, -7.59; CI, -10.0 to -5.2 ) compared to white ethnicity, as was Asian ethnicity (B coefficient, -4.23; CI, -7.11 to -1.34 ), when adjusting for age, sex, smoking status, IMD score, and practice clustering $(n=2,824)$.
Results were similar when this analysis was performed on patients with spirometry-confirmed COPD only $(n=1,509)$ (Table 5). When the severity analysis was repeated using ethnic-specific predicted $\mathrm{FEV}_{1}$ values rather than raw ECSC values, it showed no significant ethnic difference in \% predicted $\mathrm{FEV}_{1}$ for all COPD patients and for spirometryconfirmed COPD patients (Table 5). Note that some patients with a COPD diagnosis had a \% predicted $\mathrm{FEV}_{1}$ value but did not necessarily have spirometry-confirmed COPD (ie, $\mathrm{FEV}_{\mathrm{l}} / \mathrm{FVC}$ ratio $\left.<0.7\right)$.

\section{Discussion}

Black people in London were less than half as likely as white people to have a diagnosis of COPD when age, sex, smoking, deprivation, and practice clustering were taken into account (adjusted OR, 0.44; CI, 0.39-0.51). COPD drugs were equally likely to be prescribed in each ethnic group for similar severities of COPD, but LAMAs were less commonly prescribed in black people. Black COPD patients were less likely to be current smokers and much less likely to have ever smoked. Black ethnicity appeared to be a predictor of poorer lung function in COPD patients, an effect that disappeared when ethnic-specific predicted $\mathrm{FEV}_{1}$ values were used.

Diagnosis of COPD was less common in all nonwhite ethnic groups compared to white people. On subgroup analysis, the white ethnic group was heterogeneous in the distribution of COPD prevalence, with the "other white" 
subgroup significantly less likely to have COPD than the white British subgroup. The white Irish subgroup was the only subgroup more likely to have COPD than the white British subgroup.

\section{Strengths and limitations}

This study used data from a large population with a high proportion of ethnic minority groups. It is the first population study to compare ethnic differences in COPD prevalence in a population with a large minority of black subjects. Such a cross-sectional study can describe relationships, but it cannot explain them. As with any routinely collected data, the quality of data could not be independently verified. We searched for any previous smoking history in never-smokers, to overcome the underreporting of ex-smokers that is known to occur in primary care records. ${ }^{26}$ Smoking status and ethnicity were more likely to be recorded in patients with COPD. Smoking status was also more commonly recorded in white people than other ethnic groups. It is possible that lower reporting of smoking status in minority ethnic groups had a small influence on the adjustment for smoking in the comparison of COPD prevalence.

Data were not available on family history of COPD and environmental exposures, both of which are associated with higher risk of COPD. ${ }^{20,27}$ Cannabis smoking is not recorded in this dataset. Cannabis smoking is associated with respiratory symptoms and worse lung function over and above tobacco smoking. ${ }^{28}$ Black Caribbean people are known to be more likely, but black African people considerably less likely, than white people to smoke cannabis. ${ }^{29}$ It is unclear how cannabis smoking data might affect our results.

We have previously shown that up to $30 \%$ of those with a diagnosis of COPD in primary care may not have the diagnosis confirmed on spirometry. ${ }^{2}$ We chose to include all recorded COPD diagnoses on the assumption that diagnosis not confirmed on spirometry would be unlikely to be related to ethnic groups. Omitting nonconfirmed cases would risk weakening our findings and underestimating prevalence. This decision was supported by the sensitivity analysis of spirometry-confirmed COPD giving similar results.

Concepts of ethnicity and race are difficult and potentially sensitive to define. UK census ethnicity categories, used in this study, are heterogeneous and not specific. They may differ from census ethnic categories in other countries, especially with respect to the Asian group. The prevalence of COPD varied widely between ethnic groups but also within ethnic groups. For example, within the white group, "other white" people were less likely to have COPD than white British (OR,
0.55; CI, 0.46-0.67). Ethnic subgroups include people from diverse ethnic, cultural, and racial backgrounds. Nonetheless, the narrow confidence intervals of the ORs are likely to represent true underlying ethnic differences in COPD risk.

COPD appeared more severe in black people, but that difference was not maintained when ethnic-specific predicted $\mathrm{FEV}_{1}$ values were used as recommended by the BTS. ${ }^{18} \mathrm{We}$ have already described in the "Introduction" section the difficulties in interpreting spirometry data from different ethnic groups. Adjustment for ethnicity in predicting normal spirometry values is controversial and has been opposed by Burney and Hooper ${ }^{17}$ on the basis of US data showing that overall mortality increases with poorer ventilatory function, regardless of ethnicity.

While \% predicted $\mathrm{FEV}_{1}$ is one marker of severity, respiratory symptoms in COPD patients affect quality of life $^{30}$ and are likely to affect treatment-seeking behavior. Therefore, comparing symptom scores, such as the Medical Research Council (MRC) breathlessness score, between ethnic groups would be valuable. The MRC score was not available for patients in this study.

There was no evidence of ethnic differences in the medical care of COPD to judge from the distribution of recorded spirometry and drug prescribing. The exception to this observation was the lower rate of prescribing of inhaled antimuscarinics in black people. The conduct of multiple drug analyses raises the possibility that this was a spurious finding.

\section{Previous research}

Our finding of a lower likelihood of COPD in nonwhite ethnic groups was similar to that of Martin et al. ${ }^{1}$ This is the first time this observation has been made in a population with a large minority of black people. Unlike Martin et al, ${ }^{1}$ we were able to detect ethnic differences in severity, and we have shown the relevance of ethnic-specific reference values for predicted $\mathrm{FEV}_{1}$.

Although it is clear that the differences in \% predicted $\mathrm{FEV}_{1}$ between ethnic groups are statistically significant when using raw ECSC-derived predicted $\mathrm{FEV}_{1}$, the clinical significance of these differences is less clear-cut. A minimum clinically important difference for absolute $\mathrm{FEV}_{1}$ has not been definitively established, although it has been estimated at around $100 \mathrm{~mL},{ }^{31}$ or an equivalent $4 \%$ change in $\%$ predicted $\mathrm{FEV}_{1} \cdot{ }^{32}$ This would suggest that the observed B coefficient values of -7.59 for black patients and -4.23 for Asian patients might be clinically significant.

We found lower smoking rates in black people, similar to population surveys. ${ }^{33}$ Like Martin et al, ${ }^{1}$ we found that black 
and Asian COPD patients were significantly less likely to be current smokers than white people. Martin et al ${ }^{1}$ suggested this may be because black and Asian COPD patients are more likely to stop smoking. We also found that COPD patients of all ethnic groups were significantly more likely to have never smoked than white patients. This might support an alternative hypothesis that COPD in these groups is more likely to be due to risk factors other than smoking. These risk factors, for example, tuberculosis infection or biomass smoke exposure, might be more common in ethnic immigrant groups. ${ }^{27}$ It is also possible that the COPD phenotype due to these exposures is different to the COPD phenotype due to smoking. ${ }^{27}$ Such differences could explain some of the differences in severity between ethnic groups.

\section{Interpretation}

The reasons for the ethnic differences in COPD prevalence observed are likely to be complex. They could be due to broad categories of ethnic differences in access to care, ethnic differences in normal spirometry, ethnic differences in susceptibility to COPD, or ethnic differences in smoking patterns.

Poorer access to primary care in ethnic minorities might lead to later presentation with respiratory symptoms and later diagnosis with more severe disease. This could in turn lead to a similar pattern of disease to that observed in this study. We do not have firm evidence for or against this hypothesis, and we do not have access to consultation rates. In support, we found higher rates of unknown smoker status in black people, which might indicate less detailed recording. We found that spirometry was less likely to be performed on black people in the general population, but more likely to be done on black COPD patients. We found no ethnic differences in prescribing of seven classes of COPD medications, but less prescribing of LAMAs in black COPD patients.

Healthy black people have lower normal $\mathrm{FEV}_{1}$ and FVC values than white people of a comparable age and height. ${ }^{14,16,17}$ Using standard ECSC reference values would result in lower \% predicted $\mathrm{FEV}_{1}$ for a given $\mathrm{FEV}_{1}$ value. This could lead to an artifactual impression of more severe disease, when in fact the reference values being used were inappropriate. This is supported by our sensitivity analysis, which found no ethnic difference in severity when ethnicspecific normal values were used. This is a controversial subject in COPD epidemiology. Greater clarity and consensus is needed on whether spirometry reference equations should adjust for ethnicity or not.

We do not have evidence for a biological ethnic difference in susceptibility to COPD. There is some evidence from other studies of ethnic differences in risk of lung cancer. ${ }^{34}$ There is also evidence of ethnic differences in nicotine absorption, metabolism, and addictive potential, ${ }^{35,36}$ which might affect smoking behavior (such as number of cigarettes smoked and depth of inhalation) and therefore risk.

\section{Conclusion}

Black people in London were half as likely as white people to have COPD, even after adjusting for different smoking rates. Given the markedly lower smoking rates in black people, it seems plausible that there may be other ethnic differences in smoking patterns, such as number of cigarettes per day. This may account for differences in COPD risk and severity, and should be the focus for future research.

\section{Disclosure}

AG conducted this study while funded as an academic specialist trainee in primary care by Health Education South London. The funder had no involvement in study design. The authors report no other conflicts of interest in this work.

\section{References}

1. Martin A, Badrick E, Mathur R, Hull S. Effect of ethnicity on the prevalence, severity, and management of COPD in general practice. Br J Gen Pract. 2012;62(595):e76-e81.

2. White P, Thornton H, Pinnock H, Georgopoulou S, Booth HP. Overtreatment of COPD with inhaled corticosteroids - implications for safety and costs: cross-sectional observational study. PLoS One. 2013;8(10): e75221.

3. Nacul LC, Soljak M, Meade T. Model for estimating the population prevalence of chronic obstructive pulmonary disease: cross sectional data from the Health Survey for England. Popul Health Metr. 2007;5:8.

4. Young RP, Hopkins RJ. A review of the Hispanic paradox: time to spill the beans? Eur Respir Rev. 2014;23(134):439-449.

5. Eisner MD, Blanc PD, Omachi TA, et al. Socioeconomic status, race and COPD health outcomes. J Epidemiol Community Health. 2011;65(1): 26-34

6. Han MK, Curran-Everett D, Dransfield MT, et al. Racial differences in quality of life in patients with COPD. Chest. 2011;140(5): 1169-1176.

7. Cannon KT, Sarrazin MV, Rosenthal GE, Curtis A, Thomas KW, Kaldjian L. Use of mechanical and noninvasive ventilation in black and white chronic obstructive pulmonary disease patients within the veterans administration health care system. Med Care. 2009;47(1):129-133.

8. Mowls DS, Cheruvu VK, Schilz R, Zullo MD. COPD in a nationally representative sample: sociodemographic factors and co-morbidity, diagnosis method, and healthcare utilization. COPD. 2015;12(1):96-103.

9. Powell R, Davidson D, Divers J, et al. Genetic ancestry and the relationship of cigarette smoking to lung function and per cent emphysema in four race/ethnic groups: a cross-sectional study. Thorax. 2013; 68(7):634-642.

10. National Institute for Health and Clinical Excellence (NICE). Chronic Obstructive Pulmonary Disease: Management of Chronic Obstructive Pulmonary Disease in Adults in Primary and Secondary Care. London, UK: National Clinical Guideline Centre; 2010. Available from: https://www.nice.org.uk/guidance/cg101/resources/guidance-chronicobstructive-pulmonary-disease-pdf. Accessed December 5, 2013. 
11. Health and Safety Executive. Chronic Obstructive Pulmonary Disease (COPD) in Great Britain in 2014. 2014. Available from: http://www. hse.gov.uk/statistics/causdis/copd/. Accessed April 16, 2015.

12. Damiani M, J Dixon. COPD Medical Admissions in the UK. Newmarket, UK: Hayward Medical Publications; 2004.

13. Harries TH, Seed PT, Jones S, Schofield P, White P. Chronic obstructive pulmonary disease hospital admissions and drugs - unexpected positive associations: a retrospective general practice cohort study. NPJ Prim Care Respir Med. 2014;24:14006.

14. Pellegrino R, Viegi G, Brusasco V, et al. Interpretative strategies for lung function tests. Eur Respir J. 2005;26(5):948-968.

15. American Thoracic Society. Lung function testing: selection of reference values and interpretative strategies. Am Rev Respir Dis. 1991; 144(5):1202-1218.

16. Hooper R, Burney P. Cross-sectional relation of ethnicity to ventilatory function in a West London population. Int J Tuberc Lung Dis. 2013; 17(3):400-405.

17. Burney PG, Hooper RL. The use of ethnically specific norms for ventilatory function in African-American and white populations. Int J Epidemiol. 2012;41(3):782-790.

18. Bellamy D, Booker R, Connellan S, Halpin D. Spirometry in Practice. A Practical Guide to Using Spirometry in Primary Care. London, UK: British Thoracic Society; 2005.

19. Bhopal RS. Ethnicity, Race and Health in Multicultural Societies. Oxford, UK: Oxford University Press. 2007.

20. Global Initiative for Chronic Obstructive Lung Disease (GOLD). Pocket Guide to COPD Diagnosis, Management and Prevention. 2014. Available from http://www.goldcopd.org. Accessed August 13, 2015.

21. Quanjer PH, Tammeling GJ, Cotes JE, Pedersen OF, Peslin R, Yernault JC. Lung volumes and forced ventilatory flow. Report working party: standardization of lung function testing. Eur Respir J Suppl. 1993;6:5-40.

22. Office for National Statistics. A guide to comparing 1991 and 2001 Census ethnic group data. London 2006. Available from: http://www. ons.gov.uk/ons/rel/ethnicity/focus-on-ethnicity-and-identity/a-guideto-comparing-1991-and-2001-census-ethnic-group-data/index.html. Accessed August 13, 2015.

23. United States Census Bureau. Race. Available from: http://quickfacts. census.gov/qfd/meta/long_RHI525211.htm. Accessed October 28, 2015.

24. Department for Communities and Local Government. The English indices of deprivation 2010. London 2011. Available from: https:// www.gov.uk/government/uploads/system/uploads/attachment_data/ file/6871/1871208.pdf. Accessed November 12, 2014.
25. Kirkpatrick P, Dransfield MT. Racial and sex differences in chronic obstructive pulmonary disease susceptibility, diagnosis, and treatment. Curr Opin Pulm Med. 2009;15(2):100-104.

26. Mant J, Murphy M, Rose P, Vessey M. The accuracy of general practitioner records of smoking and alcohol use: comparison with patient questionnaires. J Public Health Med. 2000;22(2):198-201.

27. Tan WC, Sin DD, Bourbeau J, et al. Characteristics of COPD in neversmokers and ever-smokers in the general population: results from the CanCOLD study. Thorax. 2015;70(9):822-829.

28. Macleod J, Robertson R, Copeland L, McKenzie J, Elton R, Reid P. Cannabis, tobacco smoking, and lung function: a cross-sectional observational study in a general practice population. Br J Gen Pract. 2015; 65(631):e89-e95.

29. Office for National Statistics. Illicit drug use among adults by ethnicity and sexual orientation: drug misuse 2013 to 2014. London 2014. Available from: https://www.gov.uk/government/statistics/tables-fordrug-misuse-findings-from-the-2013-to-2014-csew. Accessed July 22, 2015.

30. Leidy NK, Murray LT, Monz BU, et al. Measuring respiratory symptoms of COPD: performance of the EXACT-Respiratory Symptoms Tool (E-RS) in three clinical trials. Respir Res. 2014;15:124.

31. Donohue JF. Minimal clinically important differences in COPD lung function. COPD. 2005;2(1):111-124.

32. Redelmeier DA, Goldstein RS, Min ST, Hyland RH. Spirometry and dyspnea in patients with COPD. When small differences mean little. Chest. 1996;109(5):1163-1168.

33. Office for National Statistics. Integrated household survey April 2010 to March 2011: experimental statistics. London 2011. Available from: http://www.ons.gov.uk/ons/dcp171778_227150.pdf. Accessed August 13, 2015.

34. Haiman CA, Stram DO, Wilkens LR, et al. Ethnic and racial differences in the smoking-related risk of lung cancer. N Engl J Med. 2006;354(4): 333-342.

35. Benowitz NL, Dains KM, Dempsey D, Wilson M, Jacob P. Racial differences in the relationship between number of cigarettes smoked and nicotine and carcinogen exposure. Nicotine Tob Res. 2011;13(9): 772-783.

36. Perez-Stable EJ, Herrera B, Jacob P, Benowitz NL. Nicotine metabolism and intake in black and white smokers. JAMA. 1998;280(2):152-156.
International Journal of COPD

\section{Publish your work in this journal}

The International Journal of COPD is an international, peer-reviewed journal of therapeutics and pharmacology focusing on concise rapid reporting of clinical studies and reviews in COPD. Special focus is given to the pathophysiological processes underlying the disease, intervention programs, patient focused education, and self management protocols.

\section{Dovepress}

This journal is indexed on PubMed Central, MedLine and CAS. The manuscript management system is completely online and includes a very quick and fair peer-review system, which is all easy to use. Visit $\mathrm{http}: / / \mathrm{www}$.dovepress.com/testimonials.php to read real quotes from published authors. 